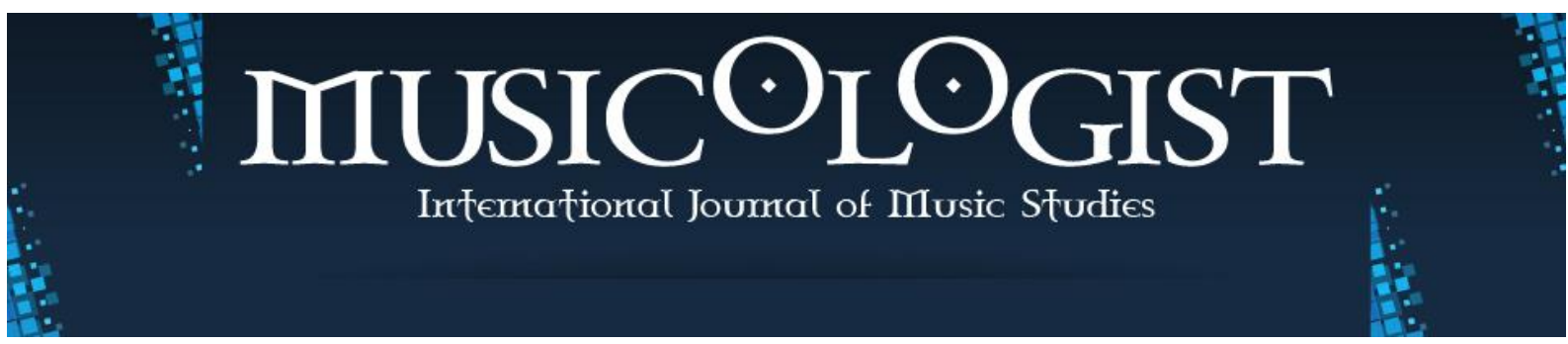

Trabzon University State Conservatory @ C 2017-2021

Volume 5 Issue $2 \quad$ December 2021

Research Article

Musicologist 2021.5 (2): 240-263

DOI: $10.33906 /$ musicologist.988011

UĞUR ASLAN

Trabzon University, Turkey

uguraslan90@hotmail.com

orcid.org/0000-0002-4421-3687

SONGÜL KARAHASANOĞLU

İstanbul Technical University, Turkey

atason@itu.edu.tr

orcid.org/0000-0003-3861-1088

\title{
Sound Ethnobiology of Musical Instruments: A Sound View of Nature in Manufacturing Kemençe
}

\begin{abstract}
Kemençe (small three-stringed fiddle) is mostly performed in the Eastern Black Sea region of Turkey. In this study, we examine the manufacturing process of kemençe considering its relationship with natural sources. Data about the production and performance of kemençe are collected by fieldwork since 2018. In this context, the first author took kemençe courses from Ilyas Parlak, a well-known kemençe player, to understand the performance of the instrument in the region. He also held interviews with the luthiers to understand the usage of the biological and non-biological materials in the making process of this instrument. In this study, we propose the term sound ethnobiology to reveal how instruments are associated with nature in relation to their manufacture and performance. We have considered the term sound ethnobiology of musical instruments into five categories which are interrelated to each other. These categories are 'bioecological sources of sound production', 'ecological knowledge of sound production', 'timbre arrangement of producing proper sound', 'traditional ecological knowledge of the sound of musical instruments', and 'ecological meanings of musical instruments'. We have put forward the manufacturing process and performances of the kemençe and its relationship to the nature in and around Trabzon by considering these five categories. Thus, we revealed that the kemençe making process is strongly tied to the interpretation of the natural sources in the region. This interpretation of the usage of the natural sources creates the traditional ecological knowledge of kemençe which is also strongly connected to its ecological meaning and the nature of the Eastern Black Sea region.
\end{abstract}

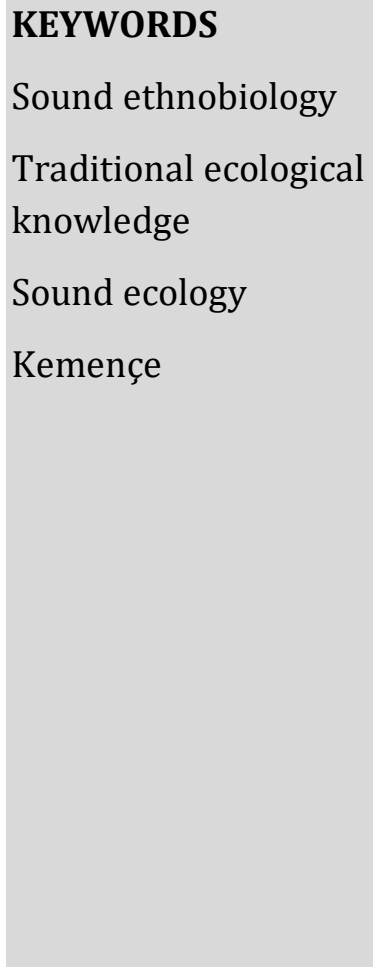




\section{Introduction}

'When the tree dies, it comes to life again as a musical instrument.'1

This statement, shared by the luthier Ceyhun Demir, is one of the discourses that reveal the relationship between instrument manufacturing and nature. First, it indicates the close relationship between the instruments with nature. Second, 'the death and revival of trees' takes place through the instruments to imply that the musical instruments are 'living creatures'. Indeed, nature is a crucial part of "the social life of musical instruments" (Bates, 2012) in many cases. This research takes this complex relationship between nature and instrument making in the context of kemençe. Indeed, the most attractive subject for me was the relation of this instrument with nature in the ethnographic work, I (Uğur Aslan) have been conducting since 2018. The relationship between kemençe and nature is at the forefront both in terms of manufacturing and performance. The pieces performed with the kemençe show us the close relationship between the local people and nature. This relationship is also important for choosing the proper tree in the manufacturing process of the instrument. The most significant indicator of this phenomenon are the discourses showing the relationship of kemençe with nature and the traditional song lyrics.

"Kemençe is a short-necked lute without a finger board. The instrument bears a marked resemblance to the mediaeval lira. The strings are stopped with the flesh of the fingers, not by lateral contact with the nails or with the back of the fingers. There is no vibrato" (Picken, 1953-1954: 76-77). Kemençe is mostly performed in the east part of the Black Sea region of Turkey, as well as Georgia and Greece due to the exchange between Greece and Turkey in 1923. It is conceivable to see kemençe in the areas where the Black Sea people migrated throughout history, mainly Chepnis and Pontic Greeks. This instrument is essential to the Black Sea culture, especially in Görele district of Giresun province and Trabzon (Akat, 2012: 1-2).

In this study, we examine the kemençe making processes and its relation to the timbre and sound that affects the performance in relation to nature. In this context, we provide an ecological perspective for the manufacturing process of kemençe. Thus, we offer a new approach, sound ethnobiology of musical instruments, which is a theoretical framework

\footnotetext{
1 “Ağaç öldüğünde enstrüman olarak tekrar canlanır.” (Demir, 2018). All translations by the authors.
} 
that considers the "social life of musical instruments" in relation to nature through an ecological perspective. In this study, while explaining the sound ethnobiology of the kemençe, we have evaluated the processes from the manufacturing process to the creation of sound communities through the instrument's relationship with nature. Indeed, in this sense, studies of sound ethnobiology share many fundamental approaches with the studies of ecomusicology in a broad sense.

Most contributions come from the disciplines of ecology and ethno/musicology to the field of ecomusicology and therefore, there are different methodologies and research techniques between these two disciplines such as applying quantitative and qualitative research (Boyle and Waterman, 2016). To distinct these two approaches, Margaret Guyette and Jennifer C. Post (2016: 42) use the definition of "ethno-ecomusicologist" that "note patterns of human behavior especially in relation to landforms and biological entities to reveal the significance of both sound and materiality (to local communities) and to demonstrate their in-depth knowledge of the land around them (expressed in time and space)".

First of all, practicing ecomusicology is a political action due to its relation to ecocriticism, environmental crisis, applied ethnomusicology (Schippers and Bendrups, 2015), and political ecology (Allen, Titon and Von Glahn, 2014), in addition to being "study of music, culture, and nature in all the complexities of those terms" (Allen, 2013). Although interest in the relationship between music and nature has a root in Ancient Greece, the relationship between humanity and the natural environment gained currency in the academy due to environmental concern since the 1970s (Allen, 2011: 391). Thus, the field of ecomusicology emerged in the early 2000s (as cited in Bock, 2017: 2) although this field has roots in ethnomusicological research in the 1970s such as Steven Feld (2003; 2012; 2015) and Anthony Seeger's (1987) transformative studies in both anthropology and ethnomusicology.

In the first part of the study, firstly, we mention the lack of sound and music-oriented studies in the literature of ethnobiology. Afterwards, we define the key elements of sound ethnobiology in parallel with organology, sound studies, sound ecology, and ethnoecology. From this point of view, we focus on the sound ethnobiology of musical instruments which consist of two main processes: instrument making and producing 
sound (performance). Thus, in the first part of the article, we cover the instrument making process which we divide into three issues. These issues are 'bioecological sources of sound production', 'ecological knowledge of sound production', and 'timbre arrangement of producing proper sound'.

In the second part of the article, we mostly focus on the performance side of the sound ethnobiology of musical instruments. We determined two issues which are related to knowledge and meaning of the sound of the musical instruments to evaluate this section. These are 'traditional ecological knowledge of the sound of musical instruments', and 'ecological meanings of musical instruments'. We also applied to sound ecology (Titon, 2020) to reveal the traditional ecological knowledge and ecological meaning in the context of sound ethnobiology.

In the last part of the study, we discussed the five issues we developed under the title of sound ethnobiology of musical instruments in the context of the kemençe. In this context, we have examined how luthiers use and engrave the natural resources in the kemençe making process. Thus, we evaluated how biological and non-biological materials affect the sound production from an ecological perspective. Of course, at the same time, in this part of the study, we have revealed how people attribute ecological meanings to the sounds produced by musical instruments and how the sounds of musical instruments might be related to the traditional ecological knowledge.

\section{Sound Ethnobiology of Musical Instruments}

Ethnobiology is a field that defined as "the study of the biological knowledge of particular ethnic groups- cultural knowledge about plants and animals and their interrelationships" (Anderson, 2011: 1). Clearly it also implies "the study of the interactions of people and the environment that is associated with human ecology and ethnoecology" (Albuquerque and Alves, 2016: 3). Although ethnobiology is methodologically and theoretically related to ethnoecology, ethnobotany and ethnozoology (Albuquerque et. al, 2019), it is possible to find commonalities between ethnobiology and ethnomusicology, sound studies, and soundscape ecology when the focus is on the sound (Wright, 2017: 59).

With this study, we propose the term sound ethnobiology for sound-oriented ethnobiological studies and evaluate this term in terms of musical instruments. While 
Claire Wright (2017: 59) mentions that sound-oriented ethnobiology studies have great potential to open new perspectives into the interdisciplinary studies of sound and music, she also states that ethnobiologists do not pay enough attention to this issue. Nevertheless, The Journal of Ethnobiology published a special issue in 2019 specific to ethnobiology studies focusing on song and music. Although we can see that music and sound studies to take place in ethnobiological studies as an important step, there are still many facts to discover about the world of sound and music practices (Llamazares and Lepofsky, 2019: 337). Especially ethnobiological studies of musical instruments are at the forefront of areas waiting to be discovered. For instance, although organology studies include the natural resources used in instrument making and their classification (Grame, 1962; Tresch and Dolan, 2013: 281), interpreting this in terms of traditional ecological knowledge ${ }^{2}$ will provide new perspectives to interpret the human activities in a certain environment.

Sound ethnobiology shares many main understandings with soundscape ecology, sound ecology, and ethnoecology. In this context, the term ethnoecology, which is frequently used in parallel with ethnobiology, can contribute to sound ethnobiology. According to Barrera- Bassols and Toledo, "ethno-ecological approach consists of interdisciplinary studies of how nature is perceived by humans through a screen of beliefs and knowledge, and how humans, through their symbolic meanings and representations, use and/or manage landscapes and natural sources" (as cited in Garrido-Perez, 2015:174). In this context, sound ethnobiology focuses on how people perceive and symbolize their environment through sound, as well as how they reflect the natural resources and landscape they live in, into their musical practices. In short, sound ethnobiology focuses on how people create traditional ecological knowledge through sound.

Sound ethnobiology of musical instruments, on the other hand, focuses on musical instruments and the sound they produce, examining traditional ecological knowledge. Indeed, musical instruments have an important potential in the production of traditional ecological knowledge. According to Kevin Dawe (2012: 195), musical instruments can be studied from many different aspects such as acoustic, ecology, and sound both

\footnotetext{
2 "Traditional ecological knowledge is a cumulative body of knowledge, practice, and belief, evolving by adaptive processes and handed down through generations by cultural transmission, about the relationship of living beings (including humans) with one another and with their environment" (Berkes 2012: 7).
} 
quantitively and qualitatively. He also indicates the term ethnobiology of musical instruments by explaining "how their (musical instruments) primary materials of flora and fauna are connected to their environment and the landscape" (Dawe, 2016: 112). Thus, we will explain and analyze the process of instrument making in terms of traditional ecological knowledge. Considering that studying musical instruments from this perspective will reveal new phenomena, and we think that using the term sound ethnobiology of musical instruments will open new directions for future studies.

In this study, we have re-evaluated Kevin Dawe's idea of "ethnobiology of musical instruments" (2016: 112) as 'sound ethnobiology of musical instruments' to establish a specific theoretical framework. Sound ethnobiology of musical instruments focuses on the sound production and its connection to the application of traditional ecological knowledge. There are three issues in analyzing a musical instrument in terms of sound ethnobiology. These issues are 'bioecological sources of sound production', 'ecological knowledge of sound production', and 'timbre arrangement of producing proper sound'. These three subjects are closely related to the instrument making process. Nevertheless, two more titles can be added in addition to this process: 'traditional ecological knowledge of the sound of musical instruments' and 'ecological meanings of musical instruments'.

The first issue of the sound ethnobiology of musical instruments is the bioecological sources of sound production. Bioecological theory is known by psychologist Urie Bronfenbrenner which focuses on human development through emphasizing the environment in which a developing individual spends time and the relations with others (Bronfenbrenner, 2005; Rosa and Tudge, 2013: 244). The fundamental part of the bioecological model is the conception of the process-person-context-time (PPCT) (Prati et. al, 2019: 31-35). In this context, bioecological sources of sound production include knowing the effect of the type of wood the instrument maker will use through spending time in nature, having a relationship with other luthiers and developing a new understanding about the usage of materials for creating a new tone color, and having a relationship with non-human actors as well as biological and non-biological materials. Of course, all these processes differ depending on the context. The act of making an instrument is a learned lifetime behavior. In this context, this process consists of the learning to make a musical instrument, the observation of other luthiers, their knowledge of relations with nature and how to use resources to produce a proper sound. 
The second issue is the ecological knowledge of sound production. Contrary to bioecological thinking, this process deals with the luthiers and musicians' relationship with the biological entities that they are surrounded and interact with. From this interaction luthiers and musicians give meaning to musical instruments and these meanings are often related to the natural sources of the musical instruments. For instance, according to Dawe (2016: 111), "the lyra is often described as a product of the mountains. It is ideally made from mountain wood. It has a body, a neck, eyes, a heart, a soul, and a voice that cries out like the spirits and animals of the mountains". As another example, the sound of qyl-qopyz has a meaning related to the sounds heard in the environment. According to Megan Rancier (2014: 389), "The qyl-qobyz possesses the ability to imitate sounds from nature, such as the sound of wind, the call of swans, or the howling of wolves".

Ecological knowledge of sound production also means that instrument makers can recognize the kind of material that produces a certain sound and timbre. The best example of this situation is John Baily's (1976) work on the dutār in Afghanistan. Although Baily does not refer to ecological thinking in this work, he provides us with ecological information of sound production as he describes in detail how the biological and non-biological materials used in instrument making are important in collective and individual invention as well as how the sound of musical instruments is affected through the materials and systems that are applied in instrument making process.

The third is the timbre arrangement of producing a proper sound. This implies producing a specific timbre, considering the material in terms of certain proportions and forms of instrument making. Timbre arrangement is directly related to the organological studies. Timbre arrangement of producing a proper sound is also related to "methodologies and techniques of acoustics, wood studies, material conservation, museum studies, and biological systematics" (Dawe, 2001: 219). Of course, for the instrument maker to achieve a certain timbre, they must know well the material they will use, know what kind of sounds can be made from natural sources, know the cultural codes and the kind of preferred timbre of the people who will listen to the instrument. This situation requires both ecological knowledge and suitable knowledge of bioecological resources. 


\section{Traditional Ecological Knowledge and Ecological Meaning of Musical Instruments}

Uncovering the nature-related meanings of instruments requires examining people's traditional ecological knowledge. In this context, ecological knowledge and meaning includes how people perform musical instruments in addition to the three items we mentioned in the previous section. The traditional ecological knowledge and ecological meaning associated with instruments has many common points with Jeff Todd Titon's (2020) idea of "sound ecology". For this reason, understanding the basic ideas of sound ecology makes it possible to analyze instruments in an ecological sense.

According to Jeff Todd Titon, sound ecology "is, first of all, a way of being in the world of sound, a sound ontology and there are four different but related aspects: 1-) sound experience announcing presence, or co-presence, 2-) sound community, 3-) sound economy, and 4-) a sound view of nature" (as cited in Bock, 2017: 5). Thus, it is possible to interpret the four components of sound ecology in the context of instruments. Indeed, this interpretation provides us with traditional ecological knowledge and ecological meaning of instruments, which is an important element of sound ethnobiology of musical instruments.

According to Titon (2013), ethnomusicology contributes to the field of ecomusicology through relational epistemologies that resulted from its methodology in "sound ecology" besides sound ontology. "A sound ecology embodies an ecological rationality aimed at who we think we are, how we know, what we know, and what we can do to bring about ecojustice in a sustainable world" (Titon, 2019: 103). Thus, interconnectedness is at the heart of ecological rationality (Titon, 2019: 104). In this context, the four aspects of sound ecology are telescopic and have a fluid structure in a certain place, landscape, and culture.

Sound announcing presence is a form of self-expression for individuals, communities, or even musical instruments. "Sound says "here I am". It says it to the sounder and to any creature who may feel sounder's vibrating resonance in its body, whether through an ear or other means of reception. Sounding locates a being in space and time" (Titon, 2015: 4). As a result of this, sound announcing presence means being by sound, co-presence, and connection (As cited in Bock, 2017: 5). There are mostly semiotic and linguistic approaches applied in terms of musical performances concerning the sound announcing presence in the context of the study of musical instruments and ethnomusicological 
studies. For instance, George Herzog's (1945) study on drum signaling in Eartern Liberia, Carol Robertson's (1976) study on Tayil, and Bahr and Haefer's (1978) work on what "blowing" means in the Piman community can be considered as examples of sound announcing presence.

According to Titon (2015: 1), cultural groups can emerge because of the commitment of communication through sound that he calls sound communities. According to Titon, music-making communities have a peak experience of sound communication among sound communities (As cited in Bock, 2017: 5). No doubt, a sound community can be created through a musical instrument and its sound. In this context, the sound announcing presence of a musical instrument has the potential to be a sound signal of a sound community. In terms of musical instruments, the timbre of certain instruments strengthens the sense of belonging to a sound community as part of musical performance such as Gourd Rattles performances in the rituals of the Suya community (Seeger, 1987), didgeridoo performance among Aborigines (Miller and Shahriari, 2017: 59), and Anzad performances of women among Tuareg people (Wendt, 2008: 261-262).

Economy and ecology are phrases with the same word origin in Greek, Oikos (household) (as cited in Bock, 2017: 5). Jeff Todd Titon (2015: 2-3) defines the term sound economy concerning the sound community and comparing it to the unsound economy. According to Titon, unsound economy is organized hierarchically but sound economy is participatory and egalitarian.

Besides, the way to handle the sound economy entirely is to apply to Marxist and NeoMarxist approaches that have economy-based thinking. In this context, the sound economy of musical instruments is best understood through the cost of materials, their turning process into commodities, value, and meta fetishism (Churton, 2000: 3-13). Martin Stokes' (2002) study about kemençe and bağlama (long-neck lute) is one of the best examples of the sound economy of musical performance, although he does not use the term sound economy. In this study, Stokes shows the attitudes of musicians about selection of musical instruments, musical materials, money, performance, and exchange.

Titon's fourth term is a sound view of nature. Sound view of nature consists of what a sound ecology might look like (As cited in Bock, 2017: 5). He also emphasizes that sound ecology is about relations and responsibility. In this context, sound ecology has a fluid- 
structure, and sustainability is one of the key terms of this. Interestingly, in this context, relations in the sound ecology can be interpreted in classic actor-network theory (ANT) which is mostly applied for the musical instruments and their relations with non-human actors and facts (De Mori, 2018: 184; Bates, 2012). From this point of view, sound ecology contains the relationship between human and non-human in terms of an ecosystem.

The traditional ecological knowledge and ecological meanings of the musical instruments provide us with a sound view of nature offered by sound ecology. In this context, people attribute ecological meanings to the sounds of musical instruments and create sound communities through traditional ecological knowledge of musical instruments. In addition, it creates a certain sound economy with the meanings attributed to the instruments and their sounds.

\section{Sound Ethnobiology of Kemençe}

The kemençe has a dynamic relationship between the environment and biota in the Eastern Black Sea region. This interaction is also prominent in the sound ethnobiology of the kemençe. In this context, topics such as the materials of kemençe, the name of the instrument parts, the interaction of the instrument's sound with the natural environment, the ecological meanings of the sound of the instrument, and the ecological knowledge in the production of the instrument constitute the sound ethnobiology of the kemençe.

It is possible to see the relationship of people with their environment in the naming of the parts of the kemençe. Thus, this relationship is also formed by the traditional ecological knowledge. The parts of the kemençe are the head (scroll), boat (soundbox), handle (neck), ear (auger), cover (soundboard), tie (keyboard), eyebrows (sound holes), frog (tailpiece), bridge, and sound post (can direği) (Balcl, 2001: 32-33). People have named these parts making an analogy with the objects they see around them and the human body parts. 


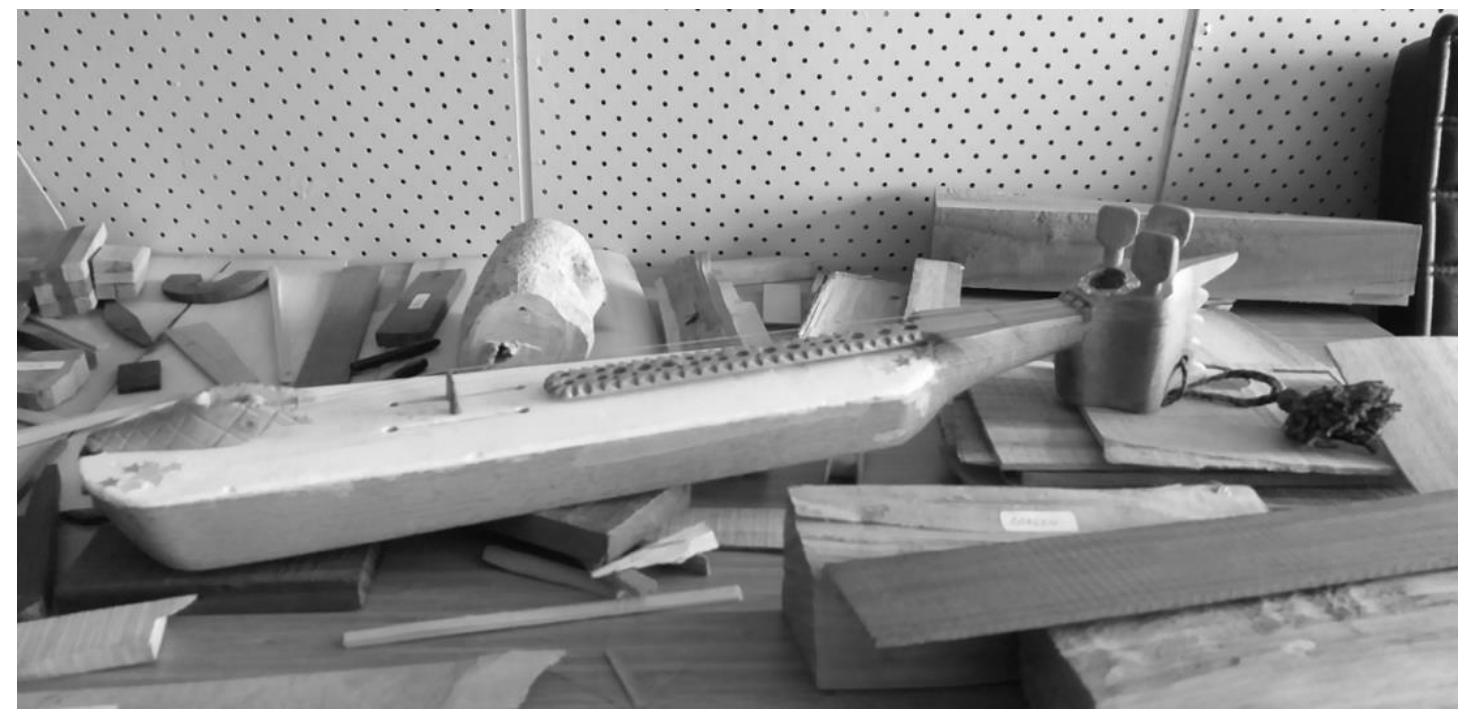

Figure 1. A kemençe with its materials used (Ceyhun Demir's archive, 2019).

Bioecological sources of the sound production in kemençe making process begin with choosing the trees. Choosing the proper tree affects the sound and timbre of the kemençe as well as help local people to create a discourse in relation to 'richness' of the timbre of kemençe. "The body of the kemençe can be made from almost any type of tree. However, the ones made of trees such as juniper, walnut, mulberry, plum, cherry, elm, ash, which can be easily shaped, do not split, and are not undeterred, are more preferred" (Demir, 2005: 85). For instance, Ali Kemal Bulut made kemençes from 54 different kinds of trees to show that this instrument has a rich timbre (Ali Kemal Bulut, personal communication, February 6, 2020). In this sense, the materials used for the instrument are symbols to raise the status of the instrument with its timbre.

The kemençe making process requires knowledge of certain techniques as well as ecological knowledge and the ability to adjust the timbre with small touches to be able to produce the right sound. Kemençe makers give a rough shape with an ax to the trunk of the tree while making the instrument. Then, they draw a template on the log in which they pre-determine the length of the instrument and cut the log according to this template. After cutting according to the template, they carve the soundbox according to the ratios. After this process, they engrave the neck (handle) and rub the instrument with emery sandpaper. Then, they attach the cover (soundboard) to the instrument. 


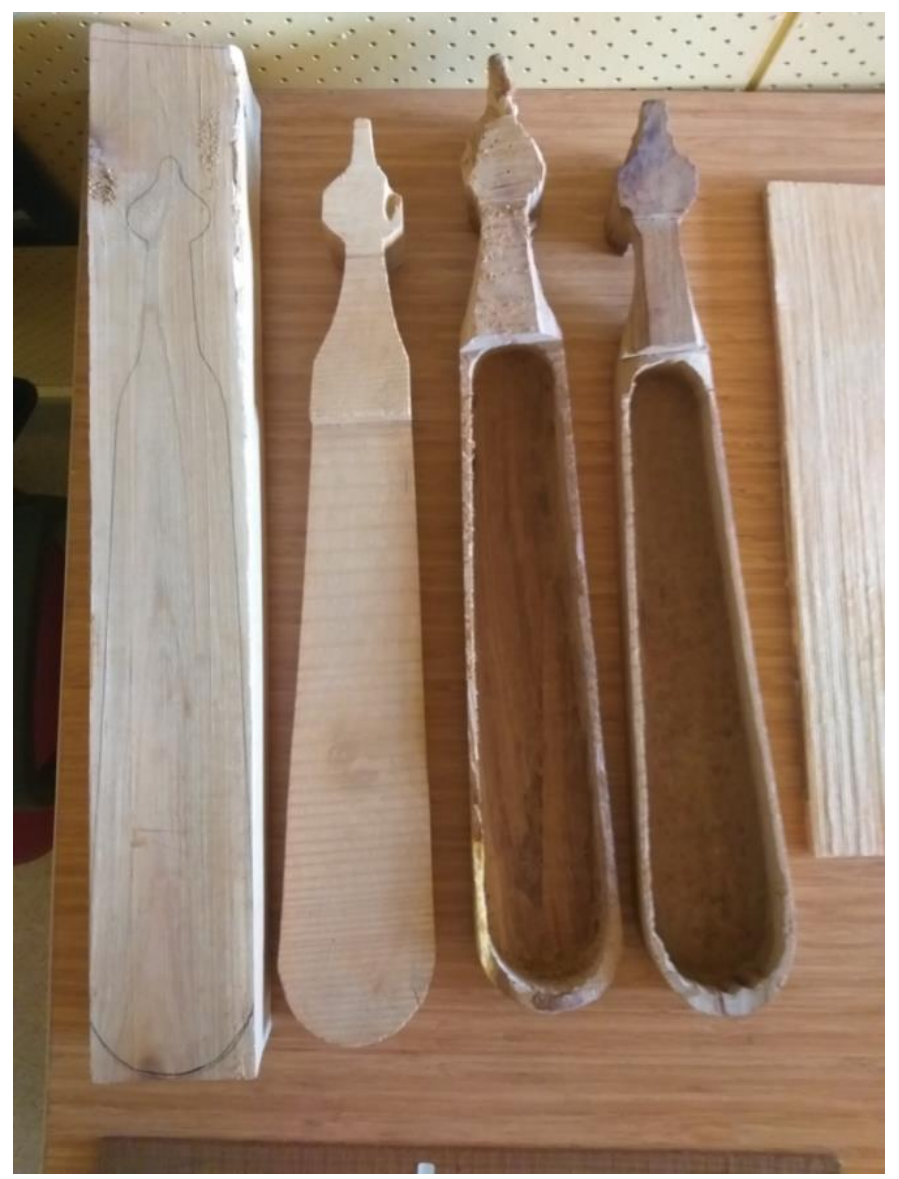

Figure 2. The process from templating the kemençe to carving the body (Ceyhun Demir's archive, 2019).

The correct preparation and affixion of the soundboard are fundamental in terms of producing a proper sound. After properly gluing the cover, they open two eyebrows (soundholes) with equal proportions on the soundboard. Then they prepare the tailpiece and affix the small parts such as augers and bridges. Finally, they string the kemençe and it is ready to play. In the next section, we will explain this situation by discussing the crucial points in terms of the timbre and sound arrangement of the kemençe.

Trees are one of the most important biological sources of kemençe. Of course, the type of wood the kemençe is made of and the environment in which the tree grows are also important. According to Hasan Sancak, a well-known kemençe maker in Trabzon, the best kemençe is made from mulberry wood. But at the same time, the place where mulberry tree grow is also very important. For example, the sound of a tree that grows on barren land is better than a tree growing on a wetted area (DiyanetTV, 2015). Consequently, luthiers prefer dry trees that grow in dry places for kemençe making. 
Ecological knowledge in making kemençe does not mean knowing only the bioecological resources. Knowing the climate and the natural conditions of the region should also be considered as an ecological knowledge of sound production. In this sense, all kemençe makers know which tree types produce a better sound from a particular climate. For instance, luthiers prefer to use juniper and wild plum for kemençes performed in the open areas such as plateau festivals and outdoors weddings, since the texture of these trees is not easily affected by moisture. Although the mulberry tree gives a very nice tone, it is easily affected by moisture. Wood pores of the mulberry tree get easily wet in a humid air and these kemençes begin to give 'hoarse voice' and 'croaky' sound. For this reason, a mulberry kemençe may vary in tone depending on the environment in which it will be performed.

The anatomy of the tree is also important in terms of the sound produced. This situation is crucial especially in terms of making the soundboard. Thus, this aspect shows us how ecological knowledge takes part in the process of the timbre arrangement for producing proper sound of kemençe. When the texture of the wood is close-grained and the annual rings (cambiums) are close to each other, the sound becomes sharper. In addition to this, the grains must come in a straight line and the parts of the tree with smooth grain must be selected. It is essential to use unbranched parts of a tree for kemençe (Mustafa Aydın, personal communication, September 20, 2019). 


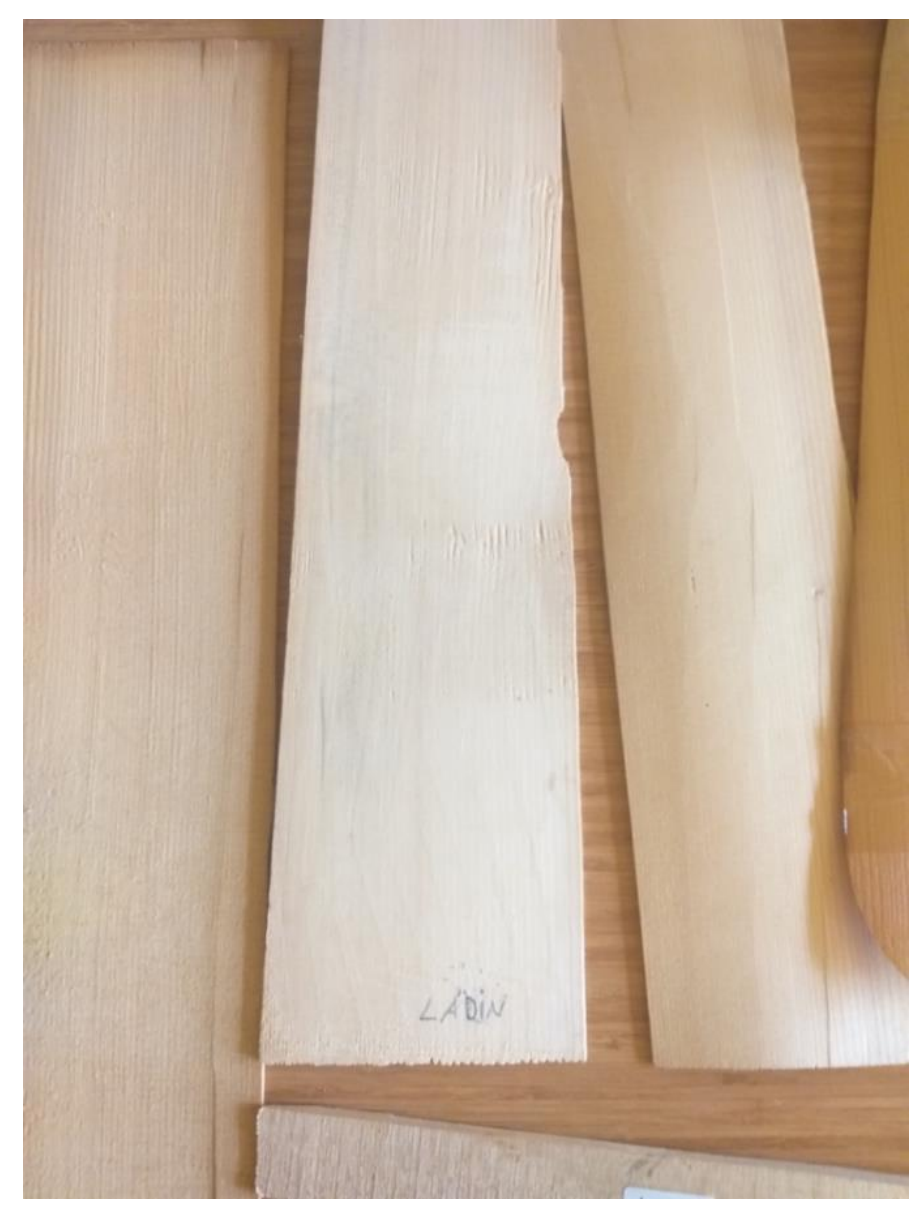

Figure 3. Spruce tree with annual rings close to each other and prepared for the cover of the high-pitched kemençe (Ceyhun Demir's archive, 2019).

Kemençe makers act responsibly in deciding which of the bioecological sources are suitable for making the soundboard of the kemençe. Then, the process of the timbre arrangement of producing a proper sound begins by engraving these resources. The grain texture of the cover (soundboard) determines the timbre of the instrument. Kemençe producers especially prefer spruce wood for the cover. This tree, which grows in the higher parts of the region, is "sliced to a thickness of about one centimeter and taken from the knot-free part near the top" (Demir, 2005: 86). This smooth piece is first wetted slightly and kept for a few days. Then they tie it to a round object to be slightly curved. After it takes the proper shape, both sides are smoothed with a grater and thinned.

The spruce tree has certain criteria to be chosen for producing a proper sound. The luthier İsmail Kırcı explains this situation as follows (personal communication January 28, 2020): 
The common feature of the instruments, the cover that gives the sound must be made of spruce and fir. In other words, spruce should be used to get the most ideal sound. But it also has a trick. Can every spruce be a cover for an instrument? It is not possible. Because the place where a tree lives, the place where it grows, and the growth direction of the tree are important. The south direction and the north direction of the tree are not the same. In short, spruce, which can be used for making a soundboard, can be changed according to its hardness-softness. Soft spruce is more suitable for a low and sonorous voice, while hard spruce is more suitable for high and metallic sound. The north side of the spruce tree has the most beautiful part. Luthiers take a part of a tree from the north direction at a distance of 10-15 $\mathrm{cm}$ from the core. When we look at this part, some streaks come upright, some of them are slanted. The flat one is soft, the steep one is harder. Perpendicular streaks are used for high-pitched sounds. Tilted ones are used for soft sounds. If it is too inclined, those streaks expand a little, and there is no problem for sound.

Although there are certain standards about the cover of the kemençe and the type of tree to be used, the variety is at the top level in terms of timbre, just like the nature. For example, many luthiers mention that there should be no knots on the cover of the instrument. However, according to İsmail Kırcl, sometimes a ramulose cover can give a good result by chance. For instance, the knot might come across the thick string side and produce rich sound. When İsmail Kırcı says, "just as the eggs of each chicken are different from each other, every kemençe is different", he associates the timbre of different kemençes with their associated bioecological sources (personal communication, January $28,2020)$.

Luthiers also use bioecological sources in terms of strings and bows in kemençe making process. While in the past the strings of kemençe were made from the intestine, today they use factory-made steel strings. Although this change, which came with technology, has an impact on the instrument in terms of timbre, the bow of the kemençe is still made by horsetail hair, used for the bow for centuries. "The strings of the bow are obtained from the tail of the male horse. Because the tail of the male horse is not damaged by urine" (Demir, 2005: 87).

We can also see the use of bioecological resources to obtain a specific timbre of kemençe with ecological knowledge in the soundpost (can direği) example. The soundpost is placed between the cover and the base of a kemençe. If a sound post is not attached to a kemençe, it gives a 'hoarse' sound. The sound post transmits the resonance from the string 
to the resonance box and it gives life to the instrument. It also determines the character of the instrument. In this context, small details such as which tree the sound post is made of, where it stands between the cover and the base, which side of the bridge is on, and which direction it faces, all affect the timbre of the instrument. According to İsmail Kircl, "the point where we put the soundpost in the kemençe is usually at the bottom of the bridge, where the thin string is. The soundpost is in the form of a rectangular prism. However, the direction of the soundpost also influences the sound color we are looking for. Whether it is upright, sideways, or oblique is related to the sound color. The soundpost must also be dry. It can be made from any tree the trunk is made of" (İsmail Kircl, personal communication, January 28, 2020).

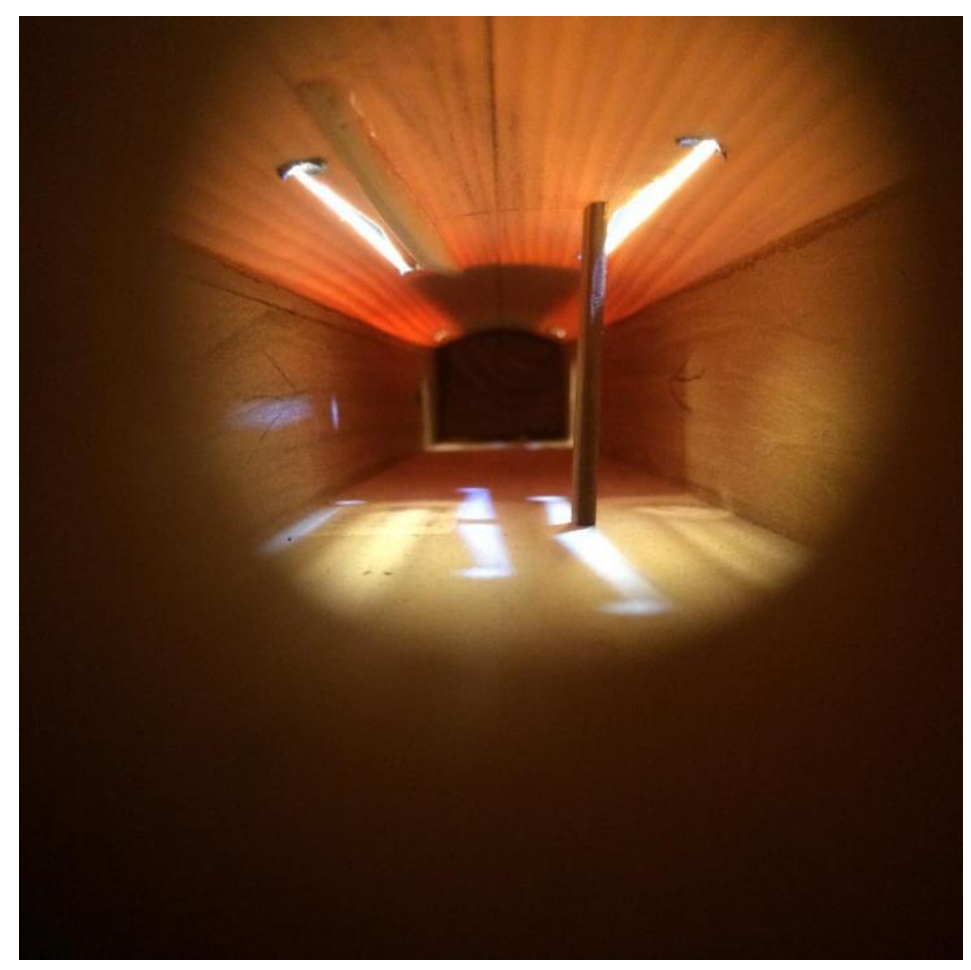

Figure 4. The soundpost of a kemençe (Ceyhun Demir's archive, 2018)

In the preparation of the cover and soundpost, such details show us the relationship of the instrument with nature. In which region the tree grows, what species it is, how it transmits sound, its texture, and its relationship with weather conditions directly affect the timbre. Thus, it is possible to encounter different types of kemençes because of this. For example, a soundboard with close rings of age is suitable for making high-pitched kemençe, while a soundboard with age rings far from each other will produce a lowpitched kemençe. High-pitched kemençe is generally performed in the west of Trabzon 
and around Görele (Akat, 2017: 4-5). The low-pitched kemençe is performed mostly indoors in the eastern part of Trabzon. As a result, it is possible to encounter various sound communities in and around Trabzon through different types of kemençes and their sounds. When we consider all this network of relations, it is seen how luthiers form and define the sounds of sound communities through engraving the bioecological sources with ecological knowledge.

\section{Traditional Ecological Knowledge and Ecological Meaning of Kemençe}

Kemençe makers are in a very close relationship with nature as well as the biological sources of the region. This situation is effective on the traditional ecological knowledge of luthiers as well as their orientation to this profession because of their relationship with nature. For example, Ceyhun Demir (Online communication, March 13, 2020), mentioned that he learned to make kemençe because his grandfather was making and playing kemençe, and he considered himself lucky to be able to live in nature. He states that he always had a piece of wood and a pocketknife. Thus, Hasan Sancak also states that he always carries a piece of wood with him and makes small kemençes from them (DiyanetTV, 2015).

The close relationship of kemençe makers with nature sometimes causes them to see the kemençe as a part of nature. In fact, some instrument makers approach the kemençe as if it were a living creature. Thus, one of the most basic reasons for the emergence of this situation is the relationship of luthiers with bioecological sources. Kemençe also has a character originating from the relationship with nature in terms of manufacturing. Oktay Üst, a luthier and performer, indicates "I approach every kemençe as if they are human. Repairing the kemençe is like raising someone from the dead. Fixing a kemençe is like reviving endangered music that my musicianship gave me" (Osman Deniz, 2012). According to Üst, covers also have a personality like a human. While he was burning the cover to prevent cracking while drilling the sound holes, he said "we are hurting the kemençe right now, but then it will play with pain" (Osman Deniz, 2012). He also mentions that there is a strong connection between kemençe, Black Sea music culture, and nature.

It is possible to read the traditional ecological knowledge and ecological meaning from the pieces performed with the kemençe. In this sense, the lyrics as well as the sound of the kemençe show us the ecological meanings of the instrument. For instance, "atma 
türküler (improvised folk songs) are sung in verses" in the Black Sea region (Pelikoğlu, 2009: 39), and the relationship between nature and the kemençe is explained in the first two lines of the quatrains, while the last two lines are mostly about love and suffering. The lyrics also refer to each part of the kemençe such as bridge, strings, and head. Thus, expressions related to nature stand out in many songs traditionally performed with kemençe. For example, in the piece titled Gitti Yarum Ormana by Koryanalı Hüseyin Köse, lyrics are "she went to the forest. She got wet. I ask the trees. To which one she was leaning on?" (Özkurt, 2015). In this example, it is seen that the trees are personalized similar to the instrument. Also, in the lyrics of the piece Ağasar Horonu performed by Apolas Lermi (2011), the words "his kemençe got wet. Its sound doesn't reach to the mountain" are tied to the nature as well as the traditional ecological knowledge of the sound of kemençe.

\section{Conclusion}

The music culture of the Eastern Black Sea region offers ethnomusicologists a diverse and rich field of research due to having a strong connection with the nature and the environment of the region. Thus, it is possible to examine this relationship through the musical instruments and lyrics performed in the region. In this study, we discussed the nature-culture relationship in a holistic way with the focus of kemençe. In this context, we have revealed the sound ethnobiology of the instrument by evaluating the instrument making and performance process. In this study, by suggesting the term sound ethnobiology, we examine how the making process and performance of the kemençe is related to the nature of the Eastern Black Sea region. As a matter of fact, in this case, we have presented the features of the term sound ethnobiology and how the instrument making process is related to these foundations.

When examining the sound ethnobiology of musical instruments, it should be emphasized how bioecological sources are handled with ecological knowledge. In this context, instrument makers know the type of bioecological resources according to creation of a unique sound color and how these sources should be shaped in the preferred way. This shows us that the ecological knowledge of the instrument makers also includes knowing the biological resources. At the same time, how luthiers make the timbre arrangement of producing proper sound is also a part of the sound ethnobiology of 
musical instruments. Clearly, timbre arrangement of a musical instrument is strongly connected to the organological way of seeing of an instrument making process. In this process, instrument makers aim to achieve a certain timbre by making minor adjustments to the instrument. Of course, the realization of this situation also depends on the ecological knowledge of the instrument maker and how well they know the bioecological resources. In addition, how the sounds of musical instruments are part of traditional ecological knowledge and how ecological meanings are attributed to these sounds are included in the content of sound ethnobiology of musical instruments.

Kemençe makers, on the other hand, evaluate the bioecological resources used in instrument making in terms of sound production and process them in line with ecological knowledge. In the process of making kemençe, luthiers can obtain different types of kemençes and various tones, especially with small changes in terms of soundboard and soundpost. Of course, this includes the issue of timbre arrangement of producing proper sound as well. Thus, with the completion of the instrument and the beginning of its performance, ecological meanings begin to be attributed to the sound of kemençe. One of the main reasons for the formation of these meanings is the traditional ecological knowledge of the people of the region. As a result, the sound ethnobiology of kemençe includes the relationship of the instrument with the nature of the Eastern Black Sea region from the production stage to the performance process. Kemençe is made using bioecological resources and then its sound is reinterpreted as a part of the nature of the Eastern Black Sea through the performance. As Demir (2018) mentioned, when the tree dies, it comes to life as an instrument and the instruments are a part of the cycle in nature. Sound ethnobiology of musical instruments, on the other hand, focuses on this cycle and aims to deal with the relationship between instruments and nature in a different dimension.

\section{REFERENCES}

Akat, Abdullah. (2012). "Çoklu Karadeniz Kemençesi” (Multi Kemanche of Black Sea). Porte Akademik. 3(2): 1-9. 
Akat, Abdullah. (2017). "Doğu Karadeniz Bölgesi Müziklerinin Popülerleşme Süreci ve Etkileşimleri," (Popularization Process of Eastern Black Sea Region Music and Its Influences), Paper presented at the Uluslararası Asya ve Kuzey Afrika Çalışmaları Kongresi, Bildiriler: Müzik Kültürü ve Eğitimi, C1, Ankara: Atatürk Kültür, Dil ve Tarih Yüksek Kurumu, (pp. 1-14). Retrieved from https://www.ayk.gov.tr/wpcontent/uploads/2015/01/AKAT-Abdullah-DOĞU-KARADENİZ-BÖLGESİMÜZIKLERININ-POPÜLERLEȘME-SÜRECİ-VE-ETKILENIMLERİ.pdf.

Allen, Aaron S. (2011). "Ecomusicology: Ecocriticism and Musicology". Journal of the American Musicological Society. 64(2): 391-394.

Allen, Aaron S. (25. 07. 2013). "Ecomusicology". Grove Music Online. Retrieved from https://www.oxfordmusiconline.com/grovemusic/view/10.1093/gmo/978156159263 $\underline{0.001 .0001 / o m o-9781561592630-e-1002240765 ~[A c c e s s e d ~} 28$ August 2020].

Allen, Aaron S., Titon, Jeff Todd and Von Glahn, Denise (2014). "Sustainability and Sound: Ecomusicology Inside and Outside the University". Music and Politics. VII (2). http://dx.doi.org/10.3998/mp.9460447.0008.205

Albuquerque, Ulysses P. and Angelo G. C. Alves. (2016). "What is Ethnobiology" Introduction to Ethnobiology, ed. Ulysses Paulino Albuquerque and Rômulo Romeu Nóbrega Alves: pp. 3-7, London: Springer.

Albuquerque, Ulysses P.; Paiva de Lucena, Reinaldo Farias; Cruz da Cunha, Luiz Vital Fernandes; Alves, Romulo Romeu Nobrega. (2019). Methods and Techniques in Ethnobiology and Ethnoecology. New York: Humana Press.

Anderson, Eguene N. (2011). "Ethnobiology: Overview of a Growing Field" Ethnobiology. Ed. E. N. Anderson, Deborah M. Pearsall, Eugene S. Hunn and Nancy J. Turner: pp. 1- 14, New Jersey: Wiley-Blackwell.

Bahr, Donald M., Haefer, J. Richard. (1978). "Song in Piman Curing”. Ethnomusicology. 22(1): 89-122.

Baily, John. (1976). "Recent Changes in the Dutār of Herat”. Asian Music. 8(1): 29-64. 
Balcı, Aydın. (2001). “Geçmişten Günümüze Karadeniz Kemençesi ve Yapımı Üzerine Çalışma" (Study on the Black Sea Kemençe and Its Production from Past to Present). Master Dissertation. Istanbul Technical University, Istanbul: Turkey.

Bates, Eliot. (2012). "The Social Life of Musical Instruments”. Ethnomusicology. 56(3): 363-395.

Berkes, Fikret. (2012). Sacred Ecology. New York: Routledge.

Bock, Cherice (26.10.2017). "Trust Author Profile: Jeff Todd Titon". Whole Terrain. Retrieved from http://www.wholeterrain.com/201704trust-author-profile-jeff-toddtiton/

Boyle, W. Alice; Waterman, Ellen. (2016). “The Ecology of Musical Performance: Towards a Robust Methodology." In Current Directions in Ecomusicology. Eds. Aaron S. Allen and Kevin Dawe: pp. 25-39. New York: Routledge.

Bronfenbrenner, Urie. (2005). Making Human Beings Human: Bioecological Perspectives on Human Development. California: SAGE.

Churton, Mel. (2000). Skills-Based Sociology: Theory and Method. London: Macmillan.

Dawe, Kevin. (2001). "People, Objects, Meaning: Recent Work on the Study and Collection of Musical Instruments". The Galpin Society Journal. 54: 219-232.

Dawe, Kevin. (2012). “The Cultural Study of Musical Instruments" The Cultural Study of Music: A Critical Introduction, Ed. Martin Clayton, Trevor Herbert and Richard Middleton: pp. 195-205. New York: Routledge.

Dawe, Kevin. (2016). "Materials Matter: Towards a Political Ecology of Musical Instruments Making" Current Directions in Ecomusicology, Ed. Aaron S. Allen and Kevin Dawe: pp. 109-121. New York: Routledge.

Demir, Ceyhun. (17.09.2018). “Ağaç öldüğünde enstrüman olarak tekrar canlanır,” (When the tree dies, it comes to life again as a musical instrument). Facebook, accessed February 21,2020 , Retrieved from 
Demir, Necati. (2005). "Trabzon ve Yöresinde Kemençe” (Kemençe in Trabzon and its Region). Karadeniz Araștırmaları. 4: 79-90.

De Mori, Berndt Brabec. (2018). "Music and Non-Human Agency" Ethnomusicology: A Contemporary Reader Volume II. Ed. Jennifer C. Post: 181-194. New York: Routledge.

DiyanetTV. (2015, 30.01.2020). Bir De Bana Sor: Hasan Sancak 90. Bölüm. [Video File]. Retrieved from https://www.youtube.com/watch?v= Z74qbw0GUA

Feld, Steven. (2003). “A Rainforest Acoustemology.” In The Auditory Culture Reader, Ed. Michell Bull and Les Back, 223-239. Oxford: Berg.

Feld, Steven. (2012). Sound and Sentiment: Birds, Weeping, Poetics, and Song in Kaluli Expression. Durham\& London: Duke University Press.

Feld, Steven. (2015). “Acoustemology.” Keywords in Sound, Eds. David Novak and Matt Sakakeeny: pp. 12-21. Durham: Duke University Press.

Fernandez-Llamazares, Alvaro; Lepofsky, Dana. (2019). "Ethnobiology Through Song". Journal of Ethnobiology. 39(3): 337-353.

Garrido-Perez, Edgardo I. (2015). "Salsa With Coconut: Challenges for Conservation Biology, Food Emphasis, and Ethno-Ecology of Afro-Caribbean Dance". Ambiente \& Sociedade. 18(4): 173-194.

Grame, Theodore C. (1962). "Bamboo and Music: A New Approach to Organology". Ethnomusicology. 6(1): 8-14.

Guyette, Margaret Q. and Post, Jennifer C. (2016). “Ecomusicology, Ethnomusicology, and Soundscape Ecology: Scientific and Musical Responses to Sound Study." In Current Directions in Ecomusicology, Ed. Aaron S. Allen and Kevin Dawe, 40-56. New York: Routledge.

Herzog, George. (1945). “Drum Signaling in a West African Tribe”. Word. 1: 217-238. 
Lermi, Apolas. (2011). Ağasar Horonu [Recorded by Apolas Lermi]. on Kalandar [CD]. Istanbul: Anadolu Tur Reklam.

Miller, Terry E.; Shahriari, Andrew. (2017). World Music: A Global Journey. New York: Routledge.

Osman Deniz. (2012, 30.01.2020). Oktay Üst- Kemençe Yapımı. [Video File]. Retrieved from https://www.youtube.com/watch?v=0VbZP8RjLfc .

Özkurt, C. Yunus (17.09.2015). Bir Türkünün Anatomisi-4 koryanali, Retrieved from http://www.koryanali.com/koryanali huseyin kose/bir turkunun anatomisi 4.pdf

Pelikoğlu, Mehmet Can. (2009) "Trabzon Yöresi Halk Müziği ve Kolbastı,” (Trabzon Area Folk Music and Kolbastı). Sanat Dergisi. 16: 37-44.

Picken, Laurence. (1953-1954). "Instrumental Polyphonic Folk Music in Asia Minor". Proceedings of the Royal Musical Association. 80: 73-86.

Prati, Laissa E.; Paula Couto, Maria Clara P. de; Poletto, Michele; de Morais, Normanda A.; Santos Poludo, Simone dos; Koller, Silivia H. (2019). "Revisiting the Ecological Engagement: New Aspects and New Research Examples". Ecological Engagement: Urie Bronfenbrenner's Method to Study Human Development. Ed. Silvia Helena Koller, Simone dos Santos Paludo, Normanda Araujo de Morais: pp. 29-48. Cham: Springer.

Rancier, Megan. (2014). “The Musical Instrument as National Archive: A Case Study of the Kazakh Qyl-qobyz". Ethnomusicology. 58(3): 379-404.

Robertson, Carol. (1976). "Tayil as a Category and Communication Among the Argentine Mapuche: A Methodological Suggestion". Yearbook of the International Folk Music Council. 8:35-52.

Rosa, Edinete Maria; Tudge, Jonathan. (2013). “Urie Bronfenbrenner's Theory of Human Development: Its Evolution From Ecology to Bioecology". Journal of Family Theory \& Review. 5: 243-258.

Schippers, Huib., and Bendrups, Dan. (2015). "Ethnomusicology, Ecology and the Sustainability of Music Cultures". The World of Music. 4(1): 9-19. 
Seeger, Anthony. (1987). Why Suya Sing: A Musical Anthropology of an Amazonian People. Cambridge: Cambridge University Press.

Stokes, Martin. (2002). "Marx, Money, and Musicians" Music and Marx: Ideas, Practices, Politics. Ed. Regula B. Qureshi: 139-163. New York: Routledge.

Titon, Jeff Todd. (2013). "The Nature of Ecomusicology". Musica e Cultura. 8(1): 8-18.

Titon, Jeff Todd. (2015). “Exhibiting Music in a Sound Community," Ethnologies. 37(1): 23-41.

Titon, Jeff Todd. (2019). "Ecojustice, Religious Folklife and a Sound Ecology”. Yale Journal of Music \& Religion. 5(2):103-116.

Titon, Jeff Todd. (2020). Toward a Sound Ecology: New and Selected Essays. Bloomington: Indiana University Press.

Tresch, John; Dolan, Emily I. (2013). “Toward a New Organology: Instruments of Music and Science". Osiris. 28(1): 278-298.

Wendt, Caroline Card. (2008). “Tuareg Music” The Garland Handbook of African Music, Ed. Ruth Stone: pp. 258-280. New York: Routledge.

Wright, Claire. (2017). "Towards an Interdisciplinary Focus on Sound in Ethnobiology Research". Ethnobiology Letters. 8(1): 58-60. 